\title{
KAJIAN ASPEK TEKNIS DAN FINASIAL USAHA RUMAH TANGGA BRIKET BIOMASSA DARI KULIT NIPAH DENGAN TEMPURUNG KELAPA
}

\author{
Martanto \\ Program Studi Agroindustri Politeknik Negeri Ketapang \\ martanto2000@yahoo.co.id
}

\begin{abstract}
ABSTRAK
Nipah merupakan salah satu tanaman didaerah pasang surut. Di Indonesia terdapat Sekitar tujuh juta hektar (7ha) tanaman Nipah. Pemanfaatan kulit nipah sampai saat ini belum maksimal. Penelitian ini mencoba membuat briket arang dengan campuran arang kelapa. Metode pernelitian ini menggunakan eksperimen untuk pembuatan briket kulit nipah dan metode kuantitatif tehadap nilai ekonomisnya. Dari hasil penelitian didapat kadar air 9,2 \%, kadar abu 3,51 $\%$ dan kadar zat menguap 2,62 \%. Hasil penelitian tersebut layak dan kulaitasnya hampir sama dengan batu bara muda. Dari perhitungan analisa finansial perhitungan NPV, IRR, Payback period B/C ratio adalah masing-masing menghasilkan nilai masing-masing adalah 8.843.001, 41 \%, 3 tahun 7 bulan dan 2,04. Sehingga usaha briket arang dari kulit nipah dengan tempurung kelapa sangat layak untuk dijadikan usaha skala rumah tangga.
\end{abstract}

Kata kunci: Briket kulit nipah, Net Present Value, IRR, Pay Back Period, B/C ratio

STUDY OF TECHNICAL AND FINANCIAL ASPECT THE BUSINESS DOMESTIC BRIQUETTE FROM BIOMASS NIPAH LEATHER WITH COCONUT SHELL

\begin{abstract}
Nipa palm is among the plants at intertidal. In Indonesia there are about seven millions ha (7ha) plants of Nipa palm. Utilization of leather nipa palm today has not been maximized. This research tried to make coal briquettes nipa palm leather with a blend of coconut charcoal. This study used experiment methods for briquetting leather nipa palm and quantitative of the economic value. This charcoal briquette have a moisture content of $9,2 \%$, ash content 3,51\%,; levels of volatile matter $2,62 \%$. The research results feasible and quality is almost the same as the brown coal.Financial analysis of calculation of NPV, IRR, Payback period $B$ / $C$ ratio is yield each value is $8,843,001,41 \%, 3.6$ years and 2,04. So that businesses charcoal leather palm leaf with coconut is very eligible to be a domestic scale business.
\end{abstract}

Keywords: Briquettes nipa palm, Net Present Value, IRR, Pay Back Period, B/Cratio

\section{PENDAHULUAN}

Nipah merupakan salah satu tumbuhan mangrove, yang hidup di iklim tropis dan tersebar merata hampir di seluruh Indonesia. Nipah atau Nypa ruticans adalah salah satu pohon anggota famili Arecaceae (palm) yang umumnya tumbuh di perairan baik tepi pantai, danau, sungai, maupun rawa-rawa (Teo, dkk., 2010). Luas tanaman nipah di seluruh Indonesia diperkirakan mencapai 
700.000 ha atau $10 \%$ dari luas lahan pasang surut yang mencapai 7 juta ha, dengan rerata populasi pohon 8.000 /ha diperkirakan total populasi nipah di Indonesia mencapai 5.600 juta pohon (Baharudin dan Taskirawati, 2009).

Selain itu, penggunaan energi biomassa cenderung murah karena bahan baku yang digunakan juga murah, ketersediaannya melimpah serta cara teknologi pengolahannya tidak terlalu rumit. Nipah (Nypa fruticans) merupakan tumbuhan yang termasuk famili palmae dan tumbuh didaerah pasang surut. Selama ini nipah hanya ditanam untuk melindungi daratan atau pantai dari abrasi air laut, padahal banyak sekali manfaat yang dapat diambil dari tanaman nipah. Hampir setiap bagian dari tumbuhan ini dapat dimanfaatkan seperti daun dimanfaatkan untuk atap rumah, nira untuk dibuat gula, dan buah untuk makanan segar atau dibuat tepung.dan kulit pada buah nipah yang tua cenderung keras, sehingga sering tidak dimanfaatkan. Sehingga dapat dijadikan sebagai bahan baku pembuat briket (Hidayat, 2006).

Briket adalah sebuah blok bahan yang dapat dibakar yang digunakan sebagai bahan bakar untuk memulai dan mempertahankan nyala api (Wikipedia, 2010). Salah satu bahan yang digunakan dalam pembuatan briket adalah kulit buah nipah yang telah dikeringkan mudah terbakar dan bersifat mudah diperbaharui (Winaya, 2008). Perekat kanji umum digunakan sebagai bahan perekat pada briket karena banyak terdapat di pasaran dan harganya relative murah. Perekat ini dalam penggunaanya menimbulkan asap yang relative sedikit dibandingkan bahan lainnya (Margono, dkk., 1993).

Penelitian ini dilakukan, kulit buah nipah dipilih sebagai bahan baku, pemilihan ini dilakukan karena kulit buah nipah di kota Ketapang ditemukan dalam jumlah yang cukup banyak dan belum dimanfaatkan secara optimal dan masih kurang dimanfaatkan terutama di Kabupaten Ketapang. Hal ini adalah sebagai perwujudan pemanfaatan energi alternatif bagi masyarakat Kabupaten Ketapang khususnya. Permasalahan dan potensi tersebut melatar belakangi penulis telah melakukan penelitian mengenai kajian aspek teknis dan ekonomis usaha briket biomassa dari kulit nipah dengan tempurung kelapa sebagai energi alternatif.

\section{METODE PENELITIAN}

Penelitian ini dilakukan dengan metode eksperiman pada analisa teknis pembuatan briket dan metode kuantitatis pada aspek ekonomisnya dan dilakukan di Laboratorium Agroindustri, Jurusan Teknologi Pertanian, Politeknik Negeri Ketapang.

\section{Aspek Teknis}

Menganalisis aspek teknis, karakter. Dari segi kuantitas yaitu dari estimasi kemampuan produksi briket arang dan dari aspek kualitas yaitu pada persentase kadar air, kadar abu dan karbon terikat dari briket kulit nipah dan arang tempurung kelapa yang dihasilkan yang ideal untuk dijadikan standar briket.

\section{Aspek Finansial}

Analisa Finansial dilakukan untuk menentukan apakah usaha yang dilakukan layak atau tidak. Kelayakan usaha pengembangan briket kulit nipah dengan arang tempurung kelapa dengan menghitungkan aspek-aspek dibawah ini. 


\section{Analisis NPV}

Analisa NPV adalah sebuah metode penilaian atas sebuah investasi yang akan dilakukan dengan menitik beratkan pada Present Value Pengeluaran dibandingkan dengan Present Value Penerimaan atau Net Present Value (NPV) merupakan selisih nilai sekarang dari penerimaan dengan nilai sekarang pengeluaran pada tingkat bunga tertentu. Rumus yang digunakan dalam penghitungan NPV (Pujawan, 2003) adalah sebagai berikut:

$N P V=\sum_{i=1}^{n} N B_{i}(1+i)^{-n}$

Dimana NB adalah net benefit yang telah diberi diskon faktor (BenefitCost), i adalah diskon faktor dan $\mathbf{n}$ adalah (waktu).

Apabila nilai NPV lebih besar atau sama dengan nol maka usaha tersebut dikatakan layak. Apabila nilai NPV sama dengan nol maka kegiatan tersebut mengembalikan nilai persis sebesar nilai Present Value. Apabila nilai NPV lebih kecil dari nol maka usaha tersebut dinyatakan tidak layak untuk dijalankan.

\section{Analisis IRR}

IRR merupakan metode perhitungan investasi dengan menghitung tingkat bunga yang menyamakan nilai sekarang investasi dengan nilai sekarang dari penerimaan-penerimaan kas bersih dimasa dating atau keadaan tingkat suku bunga pada saat nilai NPV sama dengan nol. IRR ini biasa dihitung dengan rumus sebagai berikut (Pujawan, 2003):

$$
I R R=i_{1}+\underset{(N P V-N P V)}{N P V_{1}}{ }_{2}\left(i_{2}-i_{1}\right)
$$

Dimana $\mathbf{I}_{1}$ adalah tingkat suku bunga yang menghasilkan NPV positif, $\mathbf{I}_{2}$ adalah tingkat suku bunga yang menghasilkan NPV negatif, $\mathbf{N P V}_{1}$ adalah nilai net present value yang positif dan $\mathbf{N P V _ { 2 }}$ adalah nilai net present value yang negatif.

\section{Pay Back Period}

Menurut Arifin dan Fauzi (1999), payback period adalah suatu metode dalam penentuan jangka waktu yang dibutuhkan dalam menutupi initial investment dari suatu proyek dengan menggunakan cash inflow yang dihasilkan dari proyek tersebut. Semakin pendek payback period dari periode yang disyaratkan perusahaan maka proyek investasi tersebut dapat diterima. Menurut Djarwanto Ps (2003), menyatakan bahwa payback period dapat didefinisikan sebagai berikut, payback period adalah lamanya waktu yang diperlukan untuk menutup kembali original cash outlay. Pada umumnya dikatakan lebih pendek jangka waktunya adalah lebih baik

\section{Net B/C (Net Benefit Ratio)}

$B / C$ ratio atau Benefit and Cost Ratio merupakan salah satu teori yang dapat menetukan kelayakan sebuah usaha biasanya $B / C$ ratio digunakan untuk menetukan kelayakan usaha yang berhubungan dengan kepentingan. Benefit Cost Ratio (B/C ratio) adalah perbandingan antara manfaat bersih yang bernilai 
positif dengan biaya pengeluaran suatu usaha atau kegiatan investasi dapat dikatakan layak bila diperoleh $\mathrm{B} / \mathrm{C}>1$ dan dikatakan tidak layak bila diperoleh nilai $\mathrm{B} / \mathrm{C}$ kurang dari $1(\mathrm{~B} / \mathrm{C}<1)$.

\section{HASIL DAN PEMBAHASAN \\ Aspek Teknis}

Kadar air sangat berpengaruh terhadap kualitas briket arang. Semakin tinggi kadar air akan menyebabkan kualitas briket menurun, karena akan berpengaruh terhadap nilai kalor briket arang sehingga akan sulit untuk dinyalakan. Arang sangat mudah untuk menyerap air atau arang mempunyai sifat higroskofis yang tinggi. Oleh karena itu penentuan mengenai kadar air bertujuan untuk mengetahui sifat higroskopis briket arang dari arang kulit buah nipah (Prasetyo, dkk., 2010).

Hasil pengamatan analisa kadar air (\%) db pada pembuatan briket kulit buah nipah dan tempurung kelapa dapat dilihat pada Tabel 1.

\section{Tabel 1}

\section{Hasil Pengamatan Kadar Air (\%) db}

\begin{tabular}{lll}
\hline No & Sampel & Kadar air (\%) db \\
\hline 1 & Penambahan tepung kanji 20\% & KN 2,58\%, KNT 8,20\%, dan TK 13,64\% \\
2 & Penambahan tepung kanji 30\% & KN 5,08\%, KNT 8,65\%, dan TK 14,24\% \\
3 & Penambahan tepung kanji 40\% & KN 7,59\%, KNT 3,80\%, dan TK 15,19\% \\
\hline
\end{tabular}

Sumber: Data Primer Diolah, 2015

Keterangan:

KN adalah kulit nipah, KNT adalah Kulit nipah tambah tempurung,TK adalah Tempurung kelapa.

Tabel 1, kadar air briket kulit buah nipah dengan variasi penambahan perekat tepung kanji 20\% yaitu KN 2,58\%, KNT 8,20\%, dan TK 13,64\%. Kemudian penambahan perekat tepung kanji 30\% yaitu KN 5,08\%, KNT 8,65\%, dan TK $14,24 \%$. Selanjutnya penambahan perekat tepung kanji $40 \%$ yaitu KN $7,59 \%$, KNT 3,80\%, dan TK 15,19\%. Semakin banyak penambahan perekat tepung kanji maka semakin tinggi kadar airnya bahwa pariasi penambahan tepung kanji sangat berpengaruh terhadap kadar air briket karena semakin tinggi tingkat penambahan tepung kanji, maka nilai kadar air pada briket semakin tinggi. Hasil nilai kadar air dengan variasi penambahan perekat tepung kanji $20 \%, 30 \%$, dan $40 \%$. Masih memenuhi standar kualitas kadar air menurut SNI yaitu maksimum $8 \%$, sedangkan untuk kadar air tempurung kelapa melebihi standar dari $8 \%$.

\section{Analisa Kadar Abu}

Selain kadar air, parameter lain yang juga mempengaruhi kualitas briket adalah kadar abu, kadar abu akan mempengaruhi kualitas briket sebagai absorben. Abu yang berupa oksida-oksida logam yang terdiri dari mineral yang tidak dapat menguap pada proses pengabuan. Abu merupakan bagian terbesar yang tersisa dari hasil pembakaran dalam hal ini abu yang dimaksud adalah abu sisa pembakaran briket, yang salah satu penyusunnya adalah silika dan pengaruhnya kurang baik terhadap nilai kalor briket arang yang dihasilkan (Prasetyo, dkk., 2010). 
Hasil pengamatan analisa kadar abu pada pembuatan briket kulit buah nipah dan tempurung kelapa dapat dilihat pada Tabel 2.

Tabel 2

Hasil Pengamatan Kadar Abu

\begin{tabular}{lll}
\hline No & Sampel & Kadar abu (\%) \\
\hline 1 & Penambahan tepung kanji 20\% & KN 4,03\%, KNT 3,51\% TK 2,50\% \\
2 & Penambahan tepung kanji 30\% & KN 5,85\%, KNT 3,01\% TK 7,34\% \\
3 & Penambahan tepung kanji 40\% & KN 7,07\%, KNT 7,99\% TK 1,53\% \\
\hline
\end{tabular}

Sumber: Data Primer Diolah, 2015

Keterangan :

$\mathrm{KN}=$ Kulit nipah

KNT = Kulit nipah tambah tempurung

TK = Tempurung kelapa

Tabel 2, kadar abu briket kulit buah nipah dan tempurung kelapa dengan variasi penambahan perekat tepung kanji $20 \%$ yaitu KN 4,03\%, KNT 3,51\% TK $2,50 \%$. Sedangkan variasi penambahan tepung kanji 30\% yaitu KN 5,85\%, KNT $3,01 \%$ TK $7,34 \%$. Selanjutnya penambahan perekat tepung kanji $40 \%$ yaitu KN $7,07 \%$, KNT 7,99\% TK 1,53\%. Semakin banyak penambahan perekat tepung kanji, maka semakin tinggi kadar abunya. Variasi penambahan tepung kanji sangat berpengaruh terhadap kadar abu briket karena semakin tinggi penambahan tepung kanji, maka nilai kadar abu pada briket semakin tinggi. Semakin tinggi nilai kadar abunya maka akan memperkecil nilai kalor briket sehingga dapat menurunkan kualitas briket yang akan dihasilkan. Hasil nilai kadar abu dengan variasi penambahan perekat tepung kanji $20 \%, 30 \%, 40 \%$. Masih memenuhi standar kualitas kadar abu menurut SNI yaitu $8 \%$.

\section{Analisa Kadar Zat Mudah Menguap}

Analisa kadar zat mudah menguap bertujuan untuk mengetahui jumlah zat atau senyawa yang belum menguap seperti kandungan mineral yang terdapat pada proses karbonisasi dan aktivasi. Besarnya kadar zat mudah menguap mengarah kepada kemampuan daya serap briket. Kadar zat mudah menguap yang tinggi akan mengurangi daya serap briket tesebut (Hendra dan Winarni, 2003).

Hasil pengamatan analisa kadar zat mudah menguap pada pembuatan briket kulit buah nipah dan tempurung kelapa dapat dilihat pada Tabel 3.

Tabel 3

Hasil Pengamatan Kadar Zat Mudah Menguap

\begin{tabular}{ccc}
\hline No & Sampel & Kadar abu (\%) \\
\hline 1 & Penambahan tepung kanji 20\% & KN 1,41\%, KNT 2,62\% TK 1,85\% \\
2 & Penambahan tepung kanji 30\% & KN 2,69\%, KNT 1,72\% TK 1,92\% \\
3 & Penambahan tepung kanji 40\% & KN 1,03\%, KNT 1,21\% TK 2,50\% \\
\hline
\end{tabular}

Sumber: Data Primer Diolah, 2015

Keterangan:

KN adalah kulit nipah, KNT adalah kulit nipah tambah tempurung dan TK adalah tempurung kelapa 
Tabel 3, kadar air briket kulit buah nipah dan tempurung kelapa dengan variasi penambahan perekat tepung kanji $20 \%$ yaitu KN 1,41\%, KNT 2,62\% TK $1,85 \%$, sedangkan variasi penambahan perekat tepung kanji $30 \%$ yaitu $\mathrm{KN}$ $2,69 \%$, KNT 1,72\% TK 1,92\%, selanjutnya variasi penambahan perekat tepung kanji 40\% yaitu KN 1,03\%, KNT 1,21\% TK 2,50\%. Semakin banyak penambahan perekat tepung kanji, maka semakin tinggi kadar zat mudah menguapnya, hal ini menunjukan bahwa variasi penambahan tepung kanji sangat berpengaruh terhadap kadar zat mudah menguap briket karena semakin tinggi penambahan tepung kanji, maka nilai kadar zat mudah menguap pada briket semakin tinggi. Semakin tinggi nilai kadar zat mudah menguapnya maka akan menyebabkan besarnya kadar zat mudah menguap mengarah kepada kemampuan daya serap briket.

Hasil nilai kadar zat mudah menguap dengan variasi penambahan perekat tepung kanji 20\%,30\%, dan 40\% yaitu masih memenuhi standar kualitas kadar zat mudah menguap. Menurut Sardjono (1992), tinggi rendahnya zat mudah menguap pada arang briket diduga disebabkan oleh kesempurnaan proses karbonisasi, waktu dan suhu pada proses pengarangan. Semakin besar waktu dan suhu pengarangan maka semakin banyak zat mudah menguap terbuang, sehingga pada saat pengujian kadar zat mudah menguap diperoleh rendah.

\section{Analisa Kadar Karbon Terikat}

Kadar karbon terikat adalah fraksi karbon (C) yang terikat dalam beriket arang selain fraksi air, zat mudah menguap, kadar abu. Keberadaan karbon terikat dalam briket arang dipengaruhi oleh nilai kadar abu dan zat mudah menguap. Kadarnya akan bernilai tinggi apabila kadar abu dan kadar zat mudah menguap briket rendah (Prasetyo, 2002). Hasil pengamatan analisa kadar karbon terikat pada pembuatan briket kulit buah nipah dan tempurung kelapa dapat dilihat pada Tabel 4.

\section{Tabel 4} Hasil Pengamatan Karbon Terikat

\begin{tabular}{ccc}
\hline No & Barang & Harga \\
\hline 1 & Penambahan tepung kanji 20\% & KN 91,96\%, KNT 85,65\% TK 81,98\% \\
2 & Penambahan tepung kanji 30\% & KN 86,36\%, KNT 86,60\% TK 80,32\% \\
3 & Penambahan tepung kanji 40\% & KN 89,32\%, KNT 86,98\% TK 80,76\% \\
\hline
\end{tabular}
Sumber: Data Primer Diolah, 2015

Tabel 4, kadar karbon terikat briket kulit buah nipah dan tempurung kelapa dengan variasi penambahan perekat tepung kanji $20 \%$ yaitu KN $91,96 \%$, KNT $85,65 \%$ TK $81,98 \%$, sedangkan variasi penambahan perekat tepung kanji $30 \%$ yaitu KN 86,36\%, KNT 86,60\% TK 80,32\%, selanjutnya variasi penambahan perekat tepung kanji 40\% yaitu KN 89,32\%, KNT 86,98\% TK 80,76\%. Semakin banyak penambahan perekat tepung kanji, maka semakin rendah kadar karbon terikatnya, hal tersebut dapat menunjukan bahwa variasi penambahan tepung kanji sangat berpengaruh terhadap kadar karbon terikat briket karena semakin tinggi tingkat penambahan tepung kanji, maka nilai kadar karbon terikat pada briket semakin menurun. Hasil nilai kadar karbon terikat dengan variasi penambahan perekat tepung kanji 20\%,30\%, dan 40\% yaitu melebihi standar kualitas kadar karbon terikat. Menurut Masturin (2002), karbon terikat 
berpengaruh terhadap nilai kalor bakar briket. Nilai kalor briket akan tinggi apabila nilai karbon terikatnya tinggi. Menurut penelitian, kalori biobriket adalah $5.500 \mathrm{kal}$, sebanding dengan briket batu bara (muda).

\section{Aspek Finansial}

Biaya investasi yang digunakan untuk pembuatan arang briket kulit nipah dengan tempurung kelapa diasumsikan pada Tabel 6.

Tabel 6

\section{Biaya Investasi Pembuatan Briket}

\begin{tabular}{clc}
\hline No & \multicolumn{1}{c}{ Investasi } & Harga \\
\hline 1 & Harga Mesin Pengancur Arang & Rp 3.000 .000 \\
2 & Mesin Pengaduk & Rp 3.000 .000 \\
3 & Mesin Press & Rp 2.500 .000 \\
& Total & Rp 8.500 .000 \\
\hline
\end{tabular}

Sumber: Data Primer Diolah, 2015

Dengan kapasitas Mesin press cetak briket arang biomassa 4 kg/jam, sedangkan harga bahan baku seperi dalam Tabel 7 .

Tabel 7

Biaya Bahan Baku Briket dan Pendukung ( per kg Briket)

\begin{tabular}{clc}
\hline No & \multicolumn{1}{c}{ Bahan Baku } & Harga \\
\hline 1 & Tempurung Kelapa & 500 \\
2 & Biji Nipah & (tersedia) \\
3 & Kanji Bahan Perekat & 650 \\
\hline
\end{tabular}

Sumber: Data Primer Diolah, 2015

Kapasitas produksi terpasang maksimal dengan kapasitas 4kg/jam dengan jumlah jam kerja 6jam/hari, maka dalam sebulan (25 hari kerja) maka dapat menghasilkan $600 \mathrm{~kg}$ briket perbulan kulit nipah dan tempurung kelapa.

Dari data ekspor import pada tahun 2005 briket arang tempurung kelapa Indonesia mencapai adalah 200 ton per bulan. Pada tahun 2010 permintaan domestik dalam negeri mencapai adalah 40 ton per bulan dengan daerah tujuan adalah Surabaya dan Jakarta. Permintaan ekspor luar negeri 160 ton per bulan dengan negara tujuan antara lain Jepang, Korea Selatan, Taiwan, Malaysia, Norwegia, Inggris, Perancis, Jerman, RRC, Emirat Arab dan Srilanka. Menurut informasi dari Sekretaris Jenderal Forum Komunikasi Perkelapaan Indonesia (FOKPI) Donatus G Sabon di Jakarta, menerangkan bahwa untuk pasar wilayah Eropa, saat ini Indonesia hanya mampu memenuhi kuota permintaan sekitar 10.000 ton per tahun. Permintaan tersebut belum mememenuhi pasar Asia Timur dari Korea Selatan, Jepang dan negara-negara Timur Tengah.

Dari Tabel 7, maka peluang potensi untuk mendapatkan pasar akan sangat cerah dalam dalam pasar domestik untuk memenuhi kebutuhan rumah tangga Tabel 8. 
Tabel 8

Tabel Estimasi Produksi, Penjualan dan Pendapatan Briket Arang

\begin{tabular}{cccccr}
\hline Tahun & Produksi(kg) & $\begin{array}{c}\text { Harga } \\
\text { ( Rp) }\end{array}$ & $\begin{array}{c}\text { Penjualan } \\
(\text { Rp) }\end{array}$ & $\begin{array}{c}\text { Biaya } \\
\text { Produksi } \\
\text { (Rupiah) }\end{array}$ & Pendapatan \\
\hline 1 & 2400 & 2000 & 4.800 .000 & 2.760 .000 & 2.040 .000 \\
2 & 3000 & 2260 & 6.780 .000 & 3.450 .000 & 3.330 .000 \\
3 & 3600 & 2554 & 9.194 .400 & 4.140 .000 & 5.054 .400 \\
4 & 4200 & 2886 & 12.121 .200 & 4.830 .000 & 7.291 .200 \\
5 & 4600 & 3261 & 15.652 .800 & 5.520 .000 & 10.132 .800 \\
\hline
\end{tabular}

Sumber: Data Primer Diolah, 2015

Kemudian analisa ekonomi dan dihasilkan perhitungan NPV,IRR dan B/C pada Tabel 9.

Tabel 9

Perhitungan NPV, IRR dan Payback Period

\begin{tabular}{clc}
\hline No & \multicolumn{1}{c}{ Metode Pehitungan } & Hasil Perhitungan \\
\hline 1 & Net Present Value & 8.843. 011,1 \\
2 & IRR & $41 \%$ \\
3 & Payback Period & 3,7 Tahun( 3 tahun 8 bulan) \\
4. & B/C Ratio & 2,04 \\
\hline
\end{tabular}

Sumber: Data Primer Diolah, 2015

Berdasarkan Hasil perhitungan maka nilai NPV sebesar 1.625.184,146 karena nilai NPV lebih besar dari nol ( NPV>0) maka usaha briket arang kulit nipah tersebut layak untuk dijalankan dengan tingkat waktu pengembalian Payback Period selama 3,7 tahun atau 3 tahun 7 bulan, Nilai perbandingan B/C sebesar 2,04, Usaha tersebut layak karena B/C lebih dari 1, Tingkat IRR adalah $41 \%$ lebih besar dari tingkat bunga deposito ( $13 \%$ pertahun) IRR $>i$, maka dapat dikatakan layak.

\section{PENUTUP}

Briket arang nipah dengan tempurung kelapa yang baik adalah dengan kombinasi dengan tempurung kelapa dengan penambahan tepung kanji $20 \%$ menghasilkan bahan kadar air (db), kadar abu, zat mudah menguap dan kadar karbon terikat masing masing nilai adalah 8,20\%, 3,51\%, 2,62 dan 85,65 \%. Nilai tersebut menunjukan briket kulit nipah dengan campuran tempurung kelapa dengan penambahan perekat tepung kanji sebanyak $20 \%$ kualitasnya hampir sama dengan batu bara muda, sehingga dapat dikatakan layak untuk di produksi dan memenuhi standar. Nilai aspek finansial sangat layak dengan perhitungan sebagai berikut: NPV, IRR, Payback period dan $B / C$ ratio masing-masing adalah 8.843.011,11, $41 \%$, 3,7 tahun dan 2,40.

\section{DAFTAR PUSTAKA}

Baharudin dan Taskirawati. 2009. Hasil Hutan Bukan Kayu. Fakultas Kehutanan Universitas Hassanudin. 


\section{Agriekonomika, ISSN 2301-9948 \\ e ISSN 2407-6260 \\ Volume 5, Nomor 1}

Baharuddin, M. Muin M. dan H. Bandaso. 2007. Pemanfaatan Nira Aren (Arenga pinnata Merr) Sebagai Bahan Pembuatan Gula Putih Kristal. UnhasPress. Makassar.

Hendra, D dan I. Winarni. 2003. Sifat Fisis dan Kimia Briket Arang Campuran Limbah Kayu Gergajian dan Sabetan Kayu. Buletin Penelitian Hasil Hutan 21(3): 211-226.

Hendra, D. 2007. Pembuatan Briket Arang dari Campuran Kayu, Bambu, Sabut Kelapa dan Tempurung Kelapa sebagai Sumber Alternatif. Jurnal Penelitian Hasil Hutan 25(2): 242-255

Masturin, A. 2002. Sifat Fisik dan Kimia Briket Arang dari Campuran Arang Limbah Gergajian Kayu. Skripsi. Fakultas Kehutanan, Institut Pertanian Bogor

Mulyadi, A.F. Dewi, I.A dan Deoranto, P. 2013. Pemanfaatan Kulit Buah Nipah Untuk Pembuatan Briket Bioarang Sebagai Sumber Energi Alternatif. Jurnal Teknologi Pertanian 14(1): 65-72.

Pujawan, I Nyoman. 2003. Ekonomi Teknik, Edisi Pertama.Surabaya, Guna Widya

Rangkuti, Freddy.2001 Bussiness Plan. PT Gramedia Pustaka Utama. Jakarta.

Teo S. W. F. Ang, A. F. S. L. Lok, B. R. Kurukulasuriya and H. T. W. Tan. 2010. The Status and Distribution of the Nipah Palm, Nypa fruticans Wurmb. (Arecaceae), in Singapore. Nature in Singapore 3(1): 45-52.

Winaya, I N Suprapta. 2008. Prospek Energi dari Sekam Padi dengan Teknologi Fluidized Bed Combution. http://io.ppijepang.org/old/cetak.php?id=262. Diakses 10 Juli 2008. 